\title{
Metabolic Syndrome in Female Police Officers and Female Office Workers: A Cross-Sectional Study in Occupations with Different Physical Activities
}

This article was published in the following Dove Press journal: Diabetes, Metabolic Syndrome and Obesity: Targets and Therapy

\author{
Markus Strauss ${ }^{1,2}$ \\ Peter Foshag ${ }^{2}$ \\ Anna Brzek (iD ${ }^{3}$ \\ Richard Vollenberg ${ }^{4}$ \\ Ulrich Jehn ${ }^{5}$ \\ Roman Leischik ${ }^{2}$ \\ 'Department of Cardiology I- Coronary \\ and Peripheral Vascular Disease, Heart \\ Failure Medicine, University Hospital \\ Muenster, Cardiol, Muenster 48I49, \\ Germany; ${ }^{2}$ Department of Cardiology, \\ Sector Preventive Medicine, Health \\ Promotion, Faculty of Health, School of \\ Medicine, University Witten/Herdecke, \\ Hagen 58095, Germany; ${ }^{3}$ Department of \\ Physiotherapy, Chair of Physiotherapy, \\ School of Health Sciences, Medical \\ University of Silesia, Katowice, Poland; \\ ${ }^{4}$ Department of Medicine B, \\ Gastroenterology and Hepatology, \\ University Hospital Muenster, Muenster \\ 48I49, Germany; ${ }^{5}$ Department of \\ Medicine D, Division of General Internal \\ Medicine, Nephrology and \\ Rheumatology, University Hospital of \\ Muenster, Muenster 48I49, Germany
}

Correspondence: Markus Strauss Department of Cardiology I- Coronary and Peripheral Vascular Disease, Heart Failure Medicine, University Hospital Muenster, Cardiol 48I49, Muenster, Germany

Email markus.strauss@ukmuenster.de
Introduction: Increase in the prevalence of metabolic syndrome (MetS) has become a worldwide major health problem. So far, there are limited data about the impact of occupation types and the development of metabolic risks in females. This study aimed to compare the metabolic risk profiles and in two extremely different female occupational groups: police officers (PO) and office workers (OW).

Methods: The prospective study included a total number of 97 female subjects (37 POs and $60 \mathrm{OWs)} \mathrm{from} \mathrm{Germany.} \mathrm{Anthropometric} \mathrm{characteristics,} \mathrm{metabolic} \mathrm{risk} \mathrm{parameters}$ as well as laboratory parameters were taken. The diagnosis of MetS was based on the criteria of the International Diabetes Federation (IDF).

Results: Female OWs presented a high prevalence of obesity, shown in average abdominal waist circumference $(85.3 \pm 14.5 \mathrm{~cm})$ above the threshold of $\geq 80 \mathrm{~cm}$ recommended by the IDF to define abdominal obesity. Sixty percent of OWs versus $25 \%$ of POs had an abnormal abdominal waist circumference. Concerning other metabolic risk factors (HDL, triglycerides, body mass index, blood pressure) no significant differences were found, but a tendency toward a higher prevalence of abnormal values is presented in OWs than POs. MetS was detected in almost $8 \%$ of OWs as compared with $5 \%$ in POs $(\mathrm{p}=0.705)$.

Conclusion: In an international comparison, German female POs showed one of the lowest prevalence of MetS, whereas the prevalence in OWs is equal to results in other countries. In conclusion, especially the occupational type of female OWs presented elevated factors, that are associated with increased metabolic risk. There is a relevant need for further prospective studies with larger sample sizes in female workers to determine the influence between occupational type and metabolic system.

Keywords: female office worker, female police officer, metabolic syndrome, metabolic risk factors, metabolic risk

\section{Introduction}

Increase in the prevalence of metabolic syndrome (MetS) has become a worldwide major health problem and the prevention and treatment of MetS are one of the major challenges in medicine today. The worldwide reported prevalence is between $10 \%$ and $84 \%$ depending on the ethnicity, age, gender and race of the population. ${ }^{1}$ According to the German population the prevalence of MetS is 23\%, with an upward trend. ${ }^{2}$ Proportionally, the MetS is more common in men than in women. ${ }^{3}$

MetS is defined as a constellation of interconnected biochemical, physiological, clinical and metabolic factors, including hypertension, central obesity, dyslipidemia atherosclerosis and hyperglycemia. These are increasing the risk 
of atherosclerotic cardiovascular diseases, diabetes and all-cause mortality. ${ }^{4}$ Another important determinant for MetS is a physically inactive lifestyle. ${ }^{5} \mathrm{~A}$ high physical activity leads to reduction of cardiovascular risk factors including reduced burden of obesity and blood pressure and improved lipid profiles. ${ }^{6}$ Different occupations are associated with varying levels of physical activity. ${ }^{7}$

In this study, we compared metabolic risk in females in two occupational groups that differed in their working activities: police officers (PO) and office workers $(\mathrm{OW})$. First, POs working conditions include job-related hazards as the threat of bodily injury or death, intense physical stress and unpredictable emergencies in their daily work, which is associated with high health risk. ${ }^{8}$ Therefore, good physical health is necessary and expected as it reduces physical danger considerably. Apart from that, a metabolic risk of POs is already described by some studies. ${ }^{9}$ The working condition of police officers on patrol are characterized by shift and night work and they often were without fixed feeding patterns. These are maybe all factors of influence on the development of MetS.

The second group is comprised of female OWs in public administration, a numerically large workforce with approximately 18.5 million civil servants in Germany. ${ }^{10}$ The characteristics of working condition as an $\mathrm{OW}$ are typically working in a sedentary position and get little physical exercise. It is expected that these OWs will have a greater metabolic risk and the association of sedentary time with increased metabolic risk factors and an unhealthy lifestyle is already known. ${ }^{11,12}$ Additional studies describe that OWs were at a higher risk for MetS compared with non-office workers. ${ }^{13}$

But so far, there are limited data about the impact of occupational types and the development of MetS in females. Therefore, it is of major interest to examine different female occupational groups and their metabolic risk profile and to compare these results with international data. To date, whether female OWs, an occupation with low levels of occupational physical activity, are at increased risk of metabolic risk factor compared to female POs, an occupational group with increased physical activity is not well studied. Therefore, the aim of this study is to determine the metabolic risk profile of randomly selected female OWs and POs in Germany.

\section{Materials and Methods}

\section{Study Population}

Female POs and OWs in the Ruhr area (Germany) were invited to participate in this study via internet advertisements, social media, and local corporate distribution after they responded to an official request. Participation was voluntary. We included 97 female subjects (37 POs and $60 \mathrm{OWs).} \mathrm{Inclusion} \mathrm{criteria} \mathrm{for}$ POs were working in police patrol service by shift work at the federal police force of Germany. Both groups consisted of female Caucasians. The OWs worked in tax offices or municipal administration and performed desk work. Age range was between 23 and 59 years. Desk work was characterized by a sedentary position of work in a fulltime job ( $>35$ hours per week) in accordance with the criteria of Sedentary Behavior Research Network (SBRN). ${ }^{14}$

\section{Information and Informed Consent}

The examinations followed all related tenets of the Declaration of Helsinki and the study was approved by the Human Research Ethics Committee of the University of Witten/Herdecke (application no. 121/2013). All subjects provided written informed consent.

\section{Examinations}

The examination has been performed at one time at the Sports Medicine Centre in Hagen (Research Sector Prevention, Public Health and Sports Medicine, University Witten/Herdecke) by a trained clinicians.

The medical history was collected by using a questionnaire. Participations should be refrained from eating and drinking in the last 4 to 6 hours before estimating body weight and laboratory parameters. For the collection of body weight, body composition and body height participations were informed to wear only underwear without any other clothing or shoes. Tanita BC-418MA segmental body composition analyzer was used to calculate weight and body composition. ${ }^{15}$ The laboratory tests have been implemented at the beginning of the examination to determine haematological parameters. Blood serum parameters that were analyzed included: highdensity lipoprotein (HDL), triglyceride, glycated haemoglobin (HbAlc). Venous blood sampling was taken in a seated position from an antecubital vein and then directly brought to the laboratory for analyzing (Laboratory: Laborgemeinschaft West-LG Rhein-Ruhr, Essen, Germany).

The measurement of blood pressure was conducted in a supine position, after at least 10 minutes of rest, with 
a calibrated standard blood pressure cuff. The mean of the two readings was taken as each individual's blood pressure. The measurement of waist circumference was made at the end of expiration while the subject was standing, by using a measuring tape placed around the waist at the midpoint between the lower edge of the ribs and the upper edge of the iliac crest. According to the guidelines of the International Diabetes Federation, the Diagnosis of the MetS was defined as the presence of one main trait (abdominal obesity, defined as a waist circumference $\geq 85 \mathrm{~cm}$ and $/$ or BMI $>30 \mathrm{~kg} / \mathrm{m} 2$ ) and at least two or more of the secondary traits (triglyceride $\geq$ $150 \mathrm{mg} / \mathrm{dl}$, fasting serum HDL-C $<50 \mathrm{mg} / \mathrm{dl}$, resting systolic blood pressure (RRsRest) $\geq 130 / 85 \mathrm{mmHg}$, fasting plasma glucose $\geq 100 \mathrm{mg} / \mathrm{dl}$ or already diagnosed diabetes mellitus type II). ${ }^{16}$

\section{Statistical Analysis}

For performing the statistical analysis Stata/IC 13.1 for Windows (StataCorp LP, College Station, TX) was used. Anthropometric parameters, clinical and laboratory values were categorized by mean, standard deviations (SD) and medians. Categorical characteristics were described by specifying absolute and relative frequency. Differences in anthropometric characteristics and metabolic risk factors among groups were estimated using linear regression adjusted for age because most of the analyzed parameters were directly age-related; 95\% confidence intervals (CIs) are also reported. All statistical tests were two-sided with a significance level of 0.05 .

\section{Results}

\section{Age and Professional Experience}

The average age of the POs were $31.2 \pm 6.3$ years (range 24-49) and OWs were $45.5 \pm 8.3$ years old (range 23-57) (Table 1). The difference in age between the two groups were significant $(-14.29(-17.25-11.33), \mathrm{p}<0.001)$. Therefore, in subsequent comparisons the results were adjusted for age. Participating OWs had an average professional experience of
$22.4 \pm 10.0$ (range 1.5-40) and POs $12.3 \pm 7.1$ years (range 4-31), taking into account any training period.

\section{Anthropometric Characteristics}

The parameters weight, height, BMI, muscle mass and body surface area were not significantly different between the groups. Although no significant differences were found between body fat, weight and BMI, OWs showed for all three parameters higher values than POs. BMI in the group of OWs $(26.3 \pm 5.8)$ was above the normal value of $\leq 25 \mathrm{~kg} / \mathrm{m} 2$ and thus corresponded to overweight. Table 2 describes the anthropometric measurements of the two groups. Anthropometric characteristics of both groups are shown in Table 2.

\section{Metabolic Risk Factors}

There was no significant difference between the groups of OWs and POs in waist circumference and BMI, one of the central risk factors of MetS. The average abdominal waist circumference of OWs was $85.3 \pm 14.5 \mathrm{~cm}$. This was above the threshold of $\geq 80 \mathrm{~cm}$ recommended by the IDF to define abdominal obesity, whereas the average abdominal circumference of POs was under the threshold of the IDF recommendations (Waist circumference: $77.6 \pm 11.0 \mathrm{~cm}$ ). The other considered factors (triglyceride, HDL, blood pressure, HbA1c $\%$ ) did not differ significantly between the groups (Table 3 ).

Table 4 shows the number and percentage of normal and abnormal values of risk factors that are used to assess the MetS. Before adjusting for age, significantly higher waist circumference was diagnosed in OWs than POs $(\mathrm{p}=0.001)$. But after adjustment for age, there was no significant difference anymore $(\mathrm{p}=0.558)$.

Although this correlation was abolished after adjusting for age, no statistically significant differences were found for the subdivision of the risk parameters in normal and abnormal for waist circumference, triglyceride, HDL, resting systolic blood pressure $\left(\mathrm{RR}_{\text {sRest }}\right)$, resting diastolic

Table I Age and Professional Experience of the Study Population

\begin{tabular}{|c|c|c|c|c|c|c|c|c|c|}
\hline & \multicolumn{4}{|c|}{ Office Workers } & \multicolumn{4}{|c|}{ Police Officers } & \multirow{2}{*}{$\begin{array}{l}\text { Police Officers vs Office Workers } \\
\text { Estimated Difference* } \\
(95 \%-\mathrm{Cl}) / \\
\text { p-value }\end{array}$} \\
\hline & $\mathbf{n}$ & Mean & SD & Median & $\mathbf{n}$ & Mean & SD & Median & \\
\hline Age(Years) & 60 & 45.5 & 8.3 & 47.0 & 37 & 31.2 & 6.3 & 29.0 & $-14.29(-17.25-11.33) p<0.001$ \\
\hline Professional experience (Years) & 60 & 22.4 & 10.0 & 23.0 & 37 & 12.3 & 7.1 & 10.0 & $2.77(0.59-4.95) p=0.013$ \\
\hline
\end{tabular}

Note: *Linear regression adjusted for age. 
Table 2 Anthropometric Characteristics of the Study Population

\begin{tabular}{|l|l|l|l|l|l|l|l|l|l|}
\hline & \multicolumn{3}{|l}{ Office Workers } & \multicolumn{2}{l|}{ Police Officers } & \multicolumn{2}{l|}{ Police Officers vs Office Workers } \\
\cline { 2 - 9 } & $\mathbf{n}$ & Mean & SD & Median & $\mathbf{n}$ & Mean & SD & Median & $\begin{array}{l}\text { Estimated Difference* (95\%-CI)/ } \\
\text { p-value }\end{array}$ \\
\hline Weight $(\mathrm{kg})$ & 60 & 74.2 & 16.8 & 70.3 & 37 & 69.5 & 11.9 & 66.4 & $1.85(-5.48-9.18) p=0.617$ \\
Height $(\mathrm{cm})$ & 60 & 168.0 & 6.3 & 168.0 & 37 & 171.2 & 6.1 & 171.0 & $2.30(-1.60-6.20) p=0.244$ \\
BMI (kg/m2) & 60 & 26.3 & 5.8 & 24.9 & 37 & 23.7 & 4.0 & 23.0 & $-0.06(-2.74-2.63) p=0.967$ \\
Body surface area & 60 & 1.85 & 0.21 & 1.81 & 37 & 1.81 & 0.16 & 1.80 & $0.03(-0.06-0.13) p=0.492$ \\
Muscle mass $(\mathrm{kg})$ & 60 & 46.3 & 5.7 & 45.5 & 37 & 46.9 & 4.9 & 45.4 & $2.10(-0.86-5.05) p=0.162$ \\
\% body fat & 60 & 32.9 & 7.5 & 32.2 & 37 & 28.2 & 5.9 & 27.5 & $-1.55(-5.07-1.96) p=0.383$ \\
\hline
\end{tabular}

Note: *Linear regression adjusted for age.

Table 3 Metabolic Risk Factors for Diagnosis of Metabolic Syndrome According to the IDF

\begin{tabular}{|c|c|c|c|c|c|c|c|c|c|}
\hline & \multicolumn{4}{|c|}{ Office Workers } & \multicolumn{4}{|c|}{ Police Officers } & \multirow{2}{*}{$\begin{array}{l}\text { Police Officers vs Office Workers } \\
\text { Estimated Difference* }(95 \%-\mathrm{Cl}) / \mathrm{p} \text {-value }\end{array}$} \\
\hline & $\mathbf{n}$ & Mean & SD & Median & $n$ & Mean & SD & Median & \\
\hline \multicolumn{10}{|l|}{ Central risk factors } \\
\hline Waist circumference $(\mathrm{cm})$ & 60 & 85.3 & 14.5 & 82.0 & 36 & 77.6 & 11.0 & 76.2 & $0.30(-7.01-7.62) p=0.935$ \\
\hline BMI (kg/m2) & 60 & 26.3 & 5.8 & 24.9 & 37 & 23.7 & 4.0 & 23.0 & $-0.06(-2.74-2.63) \mathrm{p}=0.967$ \\
\hline \multicolumn{10}{|l|}{ Other risk factors } \\
\hline Triglyceride (mg/dl) & 58 & 107.5 & 44.6 & 94.0 & 37 & 101.1 & 59.2 & 85.0 & $3.10(-28.74-34.95) \mathrm{p}=0.847$ \\
\hline $\mathrm{HDL}(\mathrm{mg} / \mathrm{dl})$ & 58 & 65.7 & 15.3 & 63.5 & 37 & 72.9 & 16.1 & 76.0 & $8.47(-0.96-17.90) p=0.078$ \\
\hline $\mathrm{RR}_{\text {sRest }(\mathrm{mmHg})}$ & 60 & 120.6 & 13.7 & 120.0 & 37 & 119.2 & 13.7 & 120.0 & $1.21(-6.12-8.55) p=0.743$ \\
\hline $\mathrm{RR}_{\mathrm{dRest}(\mathrm{mmHg})}$ & 60 & 80.6 & 8.5 & 80.0 & 37 & 80.4 & 8.7 & 80.0 & $0.26(-4.53-5.04) \mathrm{p}=0.915$ \\
\hline HbAlc (\%) & 56 & 5.5 & 0.9 & 5.4 & 35 & 5.2 & 0.3 & 5.2 & $-0.21(-0.56-0.13) \mathrm{p}=0.223$ \\
\hline
\end{tabular}

Note: *Linear regression adjusted for age.

blood pressure $\left(\mathrm{RR}_{\mathrm{dRest}}\right)$ and HbA1c (\%) values. But $60 \%$ of OWs versus only $25 \%$ of POs had an abnormal abdominal waist circumference. For all the other risk factors (triglycerides, HDL, blood pressure, blood sugar and BMI) there were no major differences in the number and percentage of abnormal values between the groups detectable. For all risk factors in both groups, there are more percentual participants with normal values than abnormal values (Table 4).

\section{Metabolic Syndrome}

There was no significant difference in the diagnoses of MetS between the two female groups. OWs had MetS more often than POs. According to IDF criteria, MetS was diagnosed in $8 \%(n=5)$ of OWs, but only in $5.4 \%$ $(n=2)$ of POs (Table 5). Thirty-one to forty years old OWs had the highest prevalence of MetS (20\%), whereas in the group of POs the highest prevalence was in the group $>50$ years $(66,7 \%)$.

\section{Discussion}

The day-to-day work of POs is characterized by a strong physical strain for which good physical fitness is necessary. In contrast to this, the everyday work as OW is characterized by a predominantly sedentary workload. It can be assumed that the sedentary work of OWs entails a higher metabolic risk as the occupational type of POs.

The main metabolic risk factor according to the IDF criteria is central obesity, which can be detected by waist circumference or BMI. Regarding BMI, the average value of female OWs was slightly above the normal range of $25 \mathrm{~kg} / \mathrm{m} 2$. In contrast, the average value of female POs shown no elevated average BMI. By using the BMI to detect overweight, $20 \%$ of female OWs and $8 \%$ of POs were obese. In contrast to this, high BMI values were described in previous studies about male POs. ${ }^{17}$ But previous studies have shown that waist circumference is a more precise measuring tool for assessment of obesity than BMI. ${ }^{18}$ Furthermore, Lee et $\mathrm{al}^{19}$ demonstrated that the MetS is independent of BMI. Therefore, diagnosis of obesity 
Table 4 Number and Frequency of the Presence of Normal or Abnormal Values of Risk Factors of Metabolic Syndrome According to the Criteria of the IDF $^{16}$

\begin{tabular}{|c|c|c|c|c|c|c|}
\hline & \multicolumn{2}{|c|}{ Office Workers } & \multicolumn{2}{|c|}{ Police Officers } & \multirow[t]{2}{*}{ p-value* } & \multirow[t]{2}{*}{ p-value** } \\
\hline & Normal & Abnormal & Normal & Abnormal & & \\
\hline Triglyceride $(\mathrm{mg} / \mathrm{dl})$ & 48 (82.8\%) & $10(17.2 \%)$ & 31 (83.8\%) & $6(16.2 \%)$ & 1.000 & 0.745 \\
\hline $\mathrm{HDL}(\mathrm{mg} / \mathrm{dl})$ & 52 (89.7\%) & $6(10.3 \%)$ & 33 (89.2\%) & $4(10.8 \%)$ & 1.000 & 0.699 \\
\hline $\mathrm{RR}_{\text {sRest }}(\mathrm{mmHg})$ & $42(70.0 \%)$ & $18(30.0 \%)$ & $25(67.6 \%)$ & $12(32.4 \%)$ & 0.824 & 0.555 \\
\hline $\mathrm{RR}_{\mathrm{dRest}}(\mathrm{mmHg})$ & $42(70.0 \%)$ & $18(30.0 \%)$ & $28(75.7 \%)$ & $9(24.3 \%)$ & 0.644 & 0.901 \\
\hline Blood glucose $(\mathrm{mg} / \mathrm{dl})$ & 55 (94.8\%) & $3(5.2 \%)$ & 37 (100\%) & $0(0.0 \%)$ & 0.279 & - \\
\hline Waist circumference $(\mathrm{cm})$ & 24 (40.0\%) & $36(60.0 \%)$ & 27 (75.0\%) & $9(25.0 \%)$ & 0.001 & 0.558 \\
\hline BMI (kg/m2) & 48 (80.0\%) & 12 (20.0\%) & 34 (91.9\%) & 3 (8.1\%) & 0.153 & 0.582 \\
\hline
\end{tabular}

Notes: *Exact Fisher-Test. **'Logistic regression adjusted for age.

Table 5 Diagnosis of Metabolic Syndrome (Number/Frequency) According to the Criteria of the IDF ${ }^{16}$

\begin{tabular}{|l|l|l|l|l|}
\hline & $\mathbf{n}$ & No Metabolic Syndrome & Metabolic Syndrome & p-value (Exact Fisher-Test) \\
\hline $\begin{array}{l}\text { Office workers } \\
\text { Police officers }\end{array}$ & 60 & $55(91.7 \%)$ & $5(8.3 \%)$ & 0.705 \\
\hline \multicolumn{2}{|l|}{$35(9.4 \%)$} & & \\
\hline Prevalence of Metabolic syndrome categorized in age groups & $41-50$ & $>50$ \\
\hline $\begin{array}{l}\text { Age } \\
\text { Office workers }\end{array}$ & 030 & $31-40$ & $1(4,0 \%)$ & $2(9,9 \%)$ \\
Police officers & $0(0 \%)$ & $2(20,0 \%)$ & $0(0 \%)$ & $2(66,7 \%)$ \\
\hline
\end{tabular}

should be based on the waist circumference. By considering our investigated female OWs, a strong discrepancy between abnormal values of waist circumference and BMI was found (abnormal values waist circumference: 60\%, BMI: 20\%) and using the waist circumference for diagnosing obesity seems to be more precise.

In our study, higher percentage points of abnormal abdominal circumference were detected in OWs than in POs, but after age adjusting, there was no significant difference. It is known that higher abdominal waist circumferences and the severity of a metabolic risk is associated by working longer in a sedentary position. ${ }^{20}$ Furthermore, there was no significant difference in relevant risk factors of MetS between the groups. Both groups also showed significantly lower risk parameters than their German male colleagues. Especially German male OWs have a significantly higher metabolic risk profile compared to our examined German female OWs cohort. ${ }^{21}$

Due to the different used definitions an international comparison of the prevalence of MetS in both occupational groups is difficult and the prevalence of MetS ultimately depends on the used definition. Definitions have been used by the World Health Organization (WHO), ${ }^{22}$ the National Cholesterol Education Program (NCEP), ${ }^{23}$ the
American Heart Association (AHA) and the National Heart, Lung and Blood Institute (NHLBI). ${ }^{24}$

In this study, the definition of the International Diabetes Federation (IDF) was used to diagnose the MetS. ${ }^{16}$ This definition focuses on four criteria: obesity, dyslipidemia, hypertension and insulin resistance. For the diagnosis, the main criterion of obesity and two more of the above criteria must be present.

In our studied German female cohort, the diagnosis of MetS was low. Eight point three percent of our female OWs and $5.4 \%$ of the examined female POS were diagnosed with MetS. Between the groups, there was no significant difference in diagnoses of MetS $(p=0.705)$. In both groups, the diagnosis was often more present in older than in younger participants. It may seem surprising that German female POs show a similar risk of MetS to OWs. One reason for that can be, that recent studies indicate that the timing of food intake can significantly affect metabolism and weight management. POs operating at atypical times of the 24-h day and are at risk of disturbing feeding patterns. ${ }^{25}$ On the other hand, Garbarino et $\mathrm{al}^{26}$ indicate that occupational stress at work and sleep problems in male POs are associated with an increased diagnosis of MetS. 
Table 6 Prevalence of Metabolic Syndrome in Published Studies of Police Officers and Office Workers

\begin{tabular}{|c|c|c|c|c|c|c|c|}
\hline \multicolumn{8}{|c|}{ Prevalence of Metabolic Syndrome } \\
\hline \multicolumn{4}{|l|}{ Police Officers } & \multicolumn{4}{|l|}{ Office Workers } \\
\hline Study & $\begin{array}{l}\text { Prevalence } \\
\text { (\%) }\end{array}$ & Country & Criteria & Study & $\begin{array}{l}\text { Prevalence } \\
\text { (\%) }\end{array}$ & Country & Criteria \\
\hline Own results & 5.4 & Germany & IDF & Own results & 8.3 & Germany & IDF \\
\hline Hartley et $\mathrm{al}^{30}$ & 8.8 & USA & Modified NCEP/ATP III & Lohsoonthorn et $\mathrm{al}^{33}$ & 8.2 & Thailand & Modified NCEP/ATP III \\
\hline McCanlies et $\mathrm{a}^{31}$ & 2.6 & USA & NCEP/ATP III & Konradi et al ${ }^{12}$ & 17.9 & Russia & IDF \\
\hline Janczura et $\mathrm{al}^{32}$ & 21.1 & Poland & IDF & Alavi et $\mathrm{al}^{34}$ & 20.6 & Iran & ATP III \\
\hline Zhang et a $\left.\right|^{35}$ & 3.9 & China & IDF & Matsuura et $\mathrm{al}^{36}$ & 3.4 & Japan & Japanese Criteria ${ }^{37}$ \\
\hline
\end{tabular}

In contrast to this, female groups showed significantly lower prevalence rates than the group of male OWs and POs. For example, MetS were diagnosed in 33\% of cases in a German male OW cohort. $^{21}$

In contrast to the mainly sedentary working position of OWs, POs every day on-duty work is characterized by shiftwork and rapid changes in physical demands. ${ }^{8}$ The work working conditions are characterized by physical activity. ${ }^{7}$ The protective influence of physical activity to prevent metabolic risk factors has long been known. Otherwise further studies have shown an association of shift-work and metabolic syndrome in female workers. ${ }^{27}$ It is, therefore, all the more surprising that there is no significant difference between the frequency of abnormal metabolic risk parameters and the prevalence of the MetS between the compared occupational groups. Previous studies have shown that POs are at increased cardiovascular and metabolic risk. ${ }^{28,29}$ High blood pressure is not a rare phenomenon among POs and has also been reported from other nations. ${ }^{9}$ In an international comparison, the German female POs showed one of the lowest prevalence of the MetS. In the USA, however, domestic differences were detectable. ${ }^{30,31}$ In a European comparison, Janczura et $\mathrm{al}^{32}$ were able to demonstrate a significantly higher prevalence of the MetS among Polish POs.

Lohsoonthorn et $\mathrm{al}^{33}$ reported a prevalence of $8.2 \%$ of MetS in Thai female OWs of MetS and this strongly correlates with the results of our investigated German female OWs cohort. In opposition to this, other studies from Russia and Iran showed a higher prevalence of the MetS in female OWs. ${ }^{12,34}$ The lowest prevalence was described in studies by McCanlies et $\mathrm{al}^{31}$ (USA) with $2.6 \%$ and Zhang et $\mathrm{al}^{35}$ (China) with 3.9\%. The question arises whether it is possible to transfer the findings of OWs and POs from other nations to local conditions. It should be kept in mind that there are national differences in professional activities and nutrition. Firstly, it would be important to compare our study results to other data about German female OWs and POs. An extensive literature search showed missing data about national studies. A literature review yielded no results on studies of the MetS in German female OWs and POs. A comparison of the prevalence of MetS in both groups - female OWs and POs - to international published data are shown in Table 6 .

By using the IDF definition a prevalence of $32.7 \%$ of MetS (more common in men than in women) were describe for the general German population. ${ }^{38}$ The working condition of OWs is presented by mainly sedentary work activity. This also applies to investigate our female OWs cohort. Previous investigations have already underlined the unhealthy lifestyle of office working conditions. ${ }^{12,39}$ But the female cohort has a lower metabolic health risk than the group of male OWs, wherein almost one-third of all male OWs MetS was diagnosed. ${ }^{21}$ The effects and importance of working conditions to the metabolic system have insufficiently been studied so far and tend to be clinically under-recognized, whereas the incidence of the MetS will rise dramatically. Further studies are needed to determine the influence of the type of occupation on the development of metabolic risk factors, especially in Germany. Studies in other countries have already indicated that in some cases there are important differences in the prevalence of the MetS itself and between different occupational groups. $^{40}$

\section{Conclusions}

To our knowledge, this was one of the first studies about metabolic risk in female occupation groups of OWs and POs in Germany. In conclusion, our results demonstrate that there is no significant difference in metabolic risk between female OWs and POs in Germany. These results show that there is a difference between female and male police officers. Male 
police officers have greater metabolic risk. ${ }^{7}$ This seems astonishing since it has been expected that the job of POs that requires adequate physical fitness would be accompanied by a lower metabolic risk. However, shift work and stressful job conditions in POs seem to be associated with an increased metabolic risk. When comparing the sexes, our result corresponds with previous studies that the metabolic risk of men in these occupational groups is higher than that of women. Female POs presented a tendency toward a lower prevalence and values in metabolic risk factors than OWs. Particularly female OWs tended greater abdominal waist circumference than female POs, but there was no significant difference in the diagnosis of MetS. Previous research has especially described a notable difference in metabolic risk between different male occupational groups, but data about female occupation groups are rare. In the face of mounting evidence that there is a link between occupation and metabolic risk, there is a relevant need for further prospective studies with larger sizes in female workers to determine the influence between occupational type and metabolic system.

\section{Limitations}

This study contains some limitations that limit the relevance of the results. On the one hand, the study population is a small cohort and the results can be due to small study effects. Larger prospective studies with larger size are necessary to support or refute the results. Second, the study only takes into account the confounder age. Other confounders, which may have influenced the criteria considered, were not taken into account. It is to be expected that this fact influenced the results.

\section{Abbreviations}

BMI, body mass index; HDL, high-density-lipoprotein; IDF, International Diabetes Federation; MetS, metabolic syndrome; OW, office worker; PO, police officer; $\mathrm{RR}_{\text {sRest }}$, resting systolic blood pressure; $\mathrm{RR}_{\mathrm{dRest}}$, resting diastolic blood pressure.

\section{Data Sharing Statement}

The datasets analysed during the current study are available from the corresponding author on reasonable request.

\section{Acknowledgment}

The authors thanks Hiltrud Niggemann for accuracy of the data analyses.

\section{Author Contributions}

Study conception and design: Markus Strauss, Peter Foshag, Roman Leischik. Data acquisition: Markus Strauss, Peter Foshag, Roman Leischik. Data analysis and interpretation: Markus Strauss, Peter Foshag, Roman Leischik, Richard Vollenberg Statistical analysis: Markus Strauss, Roman Leischik. Drafting the manuscript: Markus Strauss, Roman Leischik. Critical revision of the manuscript for important intellectual content: Markus Strauss, Peter Foshag, Anna Brzęk, Richard Vollenberg, Ulrich Jehn, Roman Leischik, Final approval of the version to be published: Markus Strauss, Peter Foshag, Anna Brzęk, Ulrich Jehn, Richard Vollenberg, Roman Leischik. Obtained funding: Roman Leischik. Administrative, technical, or material support: Markus Strauss, Peter Foshag, Roman Leischik.

All authors made substantial contributions to conception and design, acquisition of data, or analysis and interpretation of data; took part in drafting the article or revising it critically for important intellectual content; agreed to submit to the current journal; gave final approval of the version to be published; and agree to be accountable for all aspects of the work.

\section{Funding}

We acknowledge support from the Open Access Publication Fund of the University of Muenster.

\section{Disclosure}

The authors declare that they have no competing interests for this work.

\section{References}

1. Kaur J. A comprehensive review on metabolic syndrome. Cardiol Res Pract. 2014;2014:943162. doi:10.1155/2014/943162

2. Neuhauser H, Ellert U. rävalenz des metabolischen Syndroms in Deutschland: Eine Sensitivitätsanalyse. 12. Jahrestagung der Deutschen Arbeitsgemeinschaft für Epidemiologie. Freiburg im Breisgau. German Medical Science; 2005.

3. Prävention A Anteil der am metabolischen syndrom erkrankten in verschiedenen altersstufen der procam studie2014; 2015, Available from: http://www.assmann-stiftung.de/praevention/herzinfarkt/metabo lisches-syndrom/.

4. Wilson PW, D'Agostino RB, Parise H, Sullivan L, Meigs JB. Metabolic syndrome as a precursor of cardiovascular disease and type 2 diabetes mellitus. Circulation. 2005;112(20):3066-3072. doi:10.1161/CIRCULATIONAHA.105.539528

5. King H, Aubert RE, Herman WH. Global burden of diabetes, 1995-2025: prevalence, numerical estimates, and projections. Diabetes Care. 1998;21 (9):1414-1431. doi:10.2337/diacare.21.9.1414

6. Emerson KG, Gay J. Physical activity and cardiovascular disease among older adults: the case of race and ethnicity. J Aging Phys Act. 2017;25(4):505-509. doi:10.1123/japa.2016-0012 
7. Leischik R, Foshag P, Strauss M, et al. Aerobic capacity, physical activity and metabolic risk factors in firefighters compared with police officers and sedentary clerks. PLoS One. 2015;10(7): e0133113. doi:10.1371/journal.pone.0133113

8. Mona GG, Chimbari MJ, Hongoro C. A systematic review on occupational hazards, injuries and diseases among police officers worldwide: policy implications for the South African police service. J Occup Med Toxicol. 2019;14(1):2. doi:10.1186/s12995018-0221-x

9. Tharkar S, Kumpatla S, Muthukumaran P, Viswanathan V. High prevalence of metabolic syndrome and cardiovascular risk among police personnel compared to general population in India. $J$ Assoc Physicians India. 2008;56:845-849.

10. Berufsforschung A-U Berufe im spiegel der statistik; 2011. Available from: http://bisds.infosys.iab.de/bisds/result?beruf=BO781.

11. Healy GN, Matthews CE, Dunstan DW, Winkler EA, Owen N. Sedentary time and cardio-metabolic biomarkers in US adults: NHANES 2003-06. Eur Heart J. 2011;32(5):590-597. doi:10.1093/eurheartj/ehq451

12. Konradi AO, Rotar OP, Korostovtseva LS, et al. Prevalence of metabolic syndrome components in a population of bank employees from St. Petersburg, Russia. Metab Syndr Relat Disord. 2011;9 (5):337-343. doi:10.1089/met.2011.0028

13. Strauß M, Foshag P, Przybylek B, et al. Occupation and metabolic syndrome: is there correlation? A cross sectional study in different work activity occupations of German firefighters and office workers. Diabetol Metab Syndr. 2016;8(1):1-8. doi:10.1186/s13098-016-0174-0

14. Behaviour Research Networ S, Sedentary Behaviour Research N. Letter to the editor: standardized use of the terms "sedentary" and "sedentary behaviours". Appl Physiol Nutr Metab. 2012;37 (3):540-542. doi:10.1139/h2012-024

15. Ackland TR, Lohman TG, Sundgot-Borgen J, et al. Current status of body composition assessment in sport: review and position statement on behalf of the ad hoc research working group on body composition health and performance, under the auspices of the I.O.C. medical commission. Sports Med. 2012;42(3):227-249. doi:10.2165/ 11597140-000000000-00000

16. Alberti KG, Zimmet P, Shaw J. The metabolic syndrome-a new worldwide definition. Lancet. 2005;366(9491):1059-1062. doi:10.1016/S0140-6736(05)67402-8

17. Thayyil J, Jayakrishnan TT, Raja M, Cherumanalil JM. Metabolic syndrome and other cardiovascular risk factors among police officers. $N \mathrm{Am}$ J Med Sci. 2012;4(12):630-635. doi:10.4103/1947-2714.104313

18. Janssen I, Katzmarzyk PT, Ross R. Waist circumference and not body mass index explains obesity-related health risk. Am J Clin Nutr. 2004;79(3):379-384. doi:10.1093/ajcn/79.3.379

19. Lee WJ, Huang MT, Wang W, Lin CM, Chen TC, Lai IR. Effects of obesity surgery on the metabolic syndrome. Arch Surg. 2004;139 (10):1088-1092. doi:10.1001/archsurg.139.10.1088

20. Healy GN, Wijndaele K, Dunstan DW, et al. Objectively measured sedentary time, physical activity, and metabolic risk: the Australian diabetes, obesity and lifestyle study (AusDiab). Diabetes Care. 2008;31(2):369-371. doi:10.2337/dc07-1795

21. Strauss M, Foshag P, Leischik R. Prospective evaluation of cardiovascular, cardiorespiratory, and metabolic risk of German office workers in comparison to international data. Int J Environ Res Public Health. 2020;17(5):1590. doi:10.3390/ ijerph 17051590

22. Alberti KG, Zimmet PZ. Definition, diagnosis and classification of diabetes mellitus and its complications. Part 1: diagnosis and classification of diabetes mellitus provisional report of a WHO consultation. Diabet Med. 1998;15(7):539-553. doi:10.1002/(SICI) 1096-9136(199807)15:7<539::AID-DIA668>3.0.CO;2-S
23. Executive Summary of The Third Report of The National Cholesterol Education Program (NCEP). Expert panel on detection, evaluation, and treatment of high blood cholesterol in adults (adult treatment panel III). JAMA. 2001;285(19):2486-2497. doi:10.1001/jama.285.19.2486

24. Alberti KG, Eckel RH, Grundy SM, et al. Harmonizing the metabolic syndrome: a joint interim statement of the international diabetes federation task force on epidemiology and prevention; national heart, lung, and blood institute; American heart association; world heart federation; international atherosclerosis society; and international association for the study of obesity. Circulation. 2009;120(16):1640-1645. doi:10.1161/ CIRCULATIONAHA.109.192644

25. Kosmadopoulos A, Kervezee L, Boudreau P, et al. Effects of shift work on the eating behavior of police officers on patrol. Nutrients. 2020;12(4):999. doi:10.3390/nu12040999

26. Garbarino S, Magnavita N, Marquez-Romero JM. Sleep problems are a strong predictor of stress-related metabolic changes in police officers. A prospective study. PLoS One. 2019;14(10):e0224259e0224259. doi:10.1371/journal.pone.0224259

27. Ye HH, Jeong JU, Jeon MJ, Sakong J. The association between shift work and the metabolic syndrome in female workers. Ann Occup Environ Med. 2013;25(1):33. doi:10.1186/2052-4374-25-33

28. Plat MJ, Frings-Dresen MH, Sluiter JK. A systematic review of jobspecific workers' health surveillance activities for fire-fighting, ambulance, police and military personnel. Int Arch Occup Environ Health. 2011;84(8):839-857. doi:10.1007/s00420-011-0614-y

29. Varvarigou V, Farioli A, Korre M, Sato S, Dahabreh IJ, Kales SN. Law enforcement duties and sudden cardiac death among police officers in United States: case distribution study. BMJ. 2014;349: g6534. doi:10.1136/bmj.g6534

30. Hartley TA, Burchfiel CM, Fekedulegn D, Andrew ME, Knox SS, Violanti JM. Associations between police officer stress and the metabolic syndrome. Int J Emerg Ment Health. 2011;13(4):243-256.

31. McCanlies EC, Slaven JE, Smith LM, et al. Metabolic syndrome and sleep duration in police officers. Work. 2012;43(2):133-139. doi:10.3233/WOR-2012-1399

32. Janczura M, Bochenek G, Nowobilski R, et al. The relationship of metabolic syndrome with stress, coronary heart disease and pulmonary function-an occupational cohort-based study. PLoS One. 2015;10 (8):e0133750-e0133750. doi:10.1371/journal.pone.0133750

33. Lohsoonthorn V, Lertmaharit S, Williams MA. Prevalence of metabolic syndrome among professional and office workers in Bangkok, Thailand. J Med Assoc Thai. 2007;90(9):1908-1915.

34. Alavi SS, Makarem J, Mehrdad R, Abbasi M. Metabolic syndrome: a common problem among office workers. Int J Occup Environ Med. 2015;6(1):34-40. doi:10.15171/ijoem.2015.492

35. Zhang J, Liu Q, Long S, Guo C, Tan H. Prevalence of metabolic syndrome and its risk factors among 10,348 police officers in a large city of China: a cross-sectional study. Medicine (Baltimore). 2019;98 (40):e17306. doi:10.1097/MD.0000000000017306

36. Matsuura H, Mure K, Nishio N, Kitano N, Nagai N, Takeshita T. Relationship between coffee consumption and prevalence of metabolic syndrome among Japanese civil servants. J Epidemiol. 2012;22 (2):160-166. doi:10.2188/jea.JE20110068

37. Matsuzawa Y. Definition and the diagnostic standard for metabolic syndrome-committee to evaluate diagnostic standards for metabolic syndrome. Nihon Naika Gakkai Zasshi. 2005;94(4):794-809. doi:10.2169/naika.94.794

38. Moebus S, Hanisch JU, Aidelsburger P, Bramlage P, Wasem J, Jockel KH. Impact of 4 different definitions used for the assessment of the prevalence of the metabolic syndrome in primary healthcare: the German metabolic and cardiovascular risk project (GEMCAS). Cardiovasc Diabetol. 2007;6(1):22. doi:10.1186/1475-2840-6-22 
39. Edwardson CL, Gorely T, Davies MJ, et al. Association of sedentary behaviour with metabolic syndrome: a meta-analysis. PLoS One. 2012;7(4):e34916. doi:10.1371/journal.pone.0034916
40. Aguilar M, Bhuket T, Torres S, Liu B, Wong RJ. Prevalence of the metabolic syndrome in the United States, 2003-2012. JAMA. 2015;313(19):1973-1974. doi:10.1001/jama.2015.4260

\section{Publish your work in this journal}

Diabetes, Metabolic Syndrome and Obesity: Targets and Therapy is an international, peer-reviewed open-access journal committed to the rapid publication of the latest laboratory and clinical findings in the fields of diabetes, metabolic syndrome and obesity research. Original research, review, case reports, hypothesis formation, expert opinion and commentaries are all considered for publication. The manuscript management system is completely online and includes a very quick and fair peer-review system, which is all easy to use. Visit $\mathrm{http}: / / \mathrm{www}$.dovepress.com/testimonials.php to read real quotes from published authors. 